\title{
Feasibility of using microwave curing to enhance the compressive strength of mixed recycled aggregate powder based geopolymer
}

\author{
Jiawei Tan ${ }^{a}$, Jingming Cai ${ }^{\mathrm{a}, \mathrm{b}, *}$, Linchong Huang ${ }^{\mathrm{c}}$, Qiuning Yang ${ }^{\mathrm{d}}$, Mingjie Mao ${ }^{\mathrm{d}}$, Jiabin Li $^{\mathrm{a}, *}$ \\ ${ }^{a}$ Research Group RecyCon, Department of Civil Engineering, KU Leuven, Campus Bruges, 8200 Bruges, Belgium \\ ${ }^{\mathrm{b}}$ Department of Civil and Environmental Engineering, Faculty of Science and Technology, University of Macau, Macau, China \\ ' School of Aeronautics and Astronautics, Sun Yat-Sen University, Guangzhou, China \\ ${ }^{\mathrm{d}}$ School of Civil and Hydraulic Engineering, Ningxia University, Yinchuan, China
}

\section{H I G H L I G H T S}

- Microwave curing is effective to enhance the strength of MRAP based geopolymer.

- The microwave curing duration for MRAP based geopolymer should be limited.

- Microwave curing is more effective for geopolymer with higher solid-liquid ratio.

\section{A R T I C L E I N F O}

\section{Article history:}

Received 16 April 2020

Received in revised form 8 September 2020

Accepted 11 September 2020

\section{Keywords:}

Mixed recycled aggregate powder (MRAP)

Geopolymer binders

Compressive strength

Microwave curing

\begin{abstract}
A B S T R A C T
Geopolymerization technology provides a promising approach for mixed recycled aggregate (MRA). However, the chemical activity of ground MRA powder (MRAP) is generally low, geopolymer binders using MRAP as source material often exhibits less satisfactory performance. This paper investigates the feasibility of using microwave curing method to enhance the compressive strength of MRA based geopolymer paste through an extensive laboratory study. The effect of different parameters, including Metakaolin (MK) addition, microwave curing duration, ambient curing duration before microwave curing, alkali concentration and solid-to-liquid ratio on the efficiency of microwave curing method were examined. Meanwhile, environmental impact and cost-benefit analysis of samples cured by microwave irradiation were performed. The results showed that it is feasible to increase the compressive strength of the MRAP based geopolymer by using microwave curing. Metakaolin addition and higher solidliquid ratio can improve the efficiency of the microwave curing. A too long microwave irradiation duration may induce a compressive strength degradation of MRAP based geopolymer. The duration of ambient curing before microwave curing is recommended to be shorter than 3 days. In addition, microwave curing can significantly increase the eco-efficiency but greatly reduce the production cost of geopolymers by reducing energy consumption and increasing curing efficiency.
\end{abstract}

(c) 2020 Elsevier Ltd. All rights reserved.

\section{Introduction}

Construction and demolition waste (CDW) represent the largest waste stream in in a lot of areas [1]. It accounts for $25 \%-30 \%$ of all the waste generated in the EU [2]. From the view point of environment protection and natural resource conservation, it is necessary to process CDW into recycled aggregates for new building products. Mixed recycled aggregate (MRA) refers to those aggregates from construction and demolition waste treatment, including con-

\footnotetext{
* Corresponding authors.

E-mail addresses: jingming.cai@kuleuven.be (J. Cai), jiabin.li@kuleuven.be (J. Li).
}

crete waste, unbonded aggregate and ceramic products as their main components [3]. In Belgium, MRA accounts for approximately $35 \%$ in recycled aggregates.

Research on the use of various types of recycled aggregates in developing new building materials has been carried out since several decades, with encouraging findings [4-6]. However, previous work mainly focused on the use of recycled concrete aggregate (RCA). Limited studies $[7,8]$ have been conducted on finding applications for MRA due to the relatively lower performance of MRA based production [3,9]. Geopolymerization technology provides a promising approach for high grade use of recycled aggregates, especially MRA. This is because MRA often includes concrete waste, 
unbound aggregates and ceramic products as their main components, meaning that numerous aluminosilicate materials exist in this material.

Geopolymer has been widely regarded as a kind of environmentally friendly material and it has gained increasing interest of researchers and engineers in recent decades. Geopolymer exhibits similar mechanical behaviors as conventional Portland cement concrete while shows higher resistance to durability issues [1013]. Even though geopolymer has been developed for ages, this material has not yet achieved wide implementations in the practice [14]. Two main reasons should account for this: one is the usual requirement of elevated temperature curing and the other is the shortage of precursor materials [15]. Traditionally used aluminosilicate powders for producing geopolymer, such as fly ash and slag, are not always locally available [15]. Some previous studies [16-18] have demonstrated the possibility of producing geopolymer binders with MRA powder (MRAP). However, MRA based geopolymer often exhibits less satisfactory performance due to the relatively low chemical activity of MRAP. Therefore, methods for improving the properties of MRA based geopolymer are required.

In the manufacture of conventional geopolymer, heat providing is required during the geopolymerization process to surpass the activation barrier [19]. Geopolymer cured at ambient temperature has been reported to show lower strength development and less favorable durability [20-22]. Oven heating has been widely adopted for geopolymer curing. However, the efficiency of this method is rather low. Heat radiation consuming additional energy is inevitably generated during the heating period. Meanwhile, the initial temperature distribution in geopolymer samples is nonuniform as the heat slowly penetrates from the surface into the interior. Inefficient oven heating dramatically evokes a much higher $\mathrm{CO}_{2}$ emission. It was reported that the $\mathrm{CO}_{2}$ footprint of geopolymer concrete is only approximately $9 \%$ less than that of conventional Portland concrete [23], which can be partly explained by the oven curing method used.

There are some studies that use microwave curing as an alternative curing method. Chindaprasirt [24,25] used microwave curing for fly ash based geopolymer binders. It was found that this curing method significantly accelerates the geopolymerization process, offering much higher heating efficiency than conventional oven heating method. The microwave radiation utilizes short, high-frequency waves that can easily penetrate the geopolymer matrix. The waves intensively agitate the water molecules among the matrix and provide a more uniform heating. Ahmed et al. [26] studied the strength development of geopolymer cured by short periods of microwave and oven curing and found that geopolymers cured with microwave got strength in much shorter time than oven curing.

Previous studies mostly deal with the effect of micro curing on geopolymers using traditional aluminosilicate powders for producing geopolymer binders, such as fly ash and slag. This study has investigated the feasibility of using microwave curing method to enhance the compressive strength of MRAP based geopolymer binders. Metakaolin (MK) was introduced into the matrix to improve the properties of the geopolymer binders. The influence of different parameters, including MK addition, ambient curing duration, microwave curing duration, alkali concentration and solid-toliquid ratio on curing efficiency were examined. The compressive strength of the sample was tested. The particle morphologies of precursor and samples were observed by scanning electron microscopy (SEM) while the crystalline phases were identified by X-ray diffraction (XRD).

\section{Experiment program}

\subsection{Materials}

The used MRA, as shown in Fig. 1, were supplied by a local recycling plant in Flanders, Belgium. Different components, i.e., waste concrete ( $50 \%$ by weight), red brick ( $42 \%$ by weight), ceramic roof tile ( $5 \%$ by weight), glassy materials ( $2 \%$ by weight) and other materials can be found in raw materials. The MRA was firstly washed to remove the possible dust on the surface. An electric ball mill machine (48-D0500/G, Controls Group) was then applied to grind the MRA into powders. The duration of the milling process was $8 \mathrm{~h}$ with 16,000 times poundings.

The macro and micro morphologies of precursors (MRAP and MK) are shown in Figs. 2 and 3, respectively. The chemical compositions of the MRAP and MK are shown in Table 1. Siliconaluminate material accounts for around 53\% in MRAP, while 93.9\% in MK. MK was added for introducing more Si and Al species into the matrix. The particle size distribution curves of the MRAP and MK are shown in Fig. 4. The particle size for MK is generally

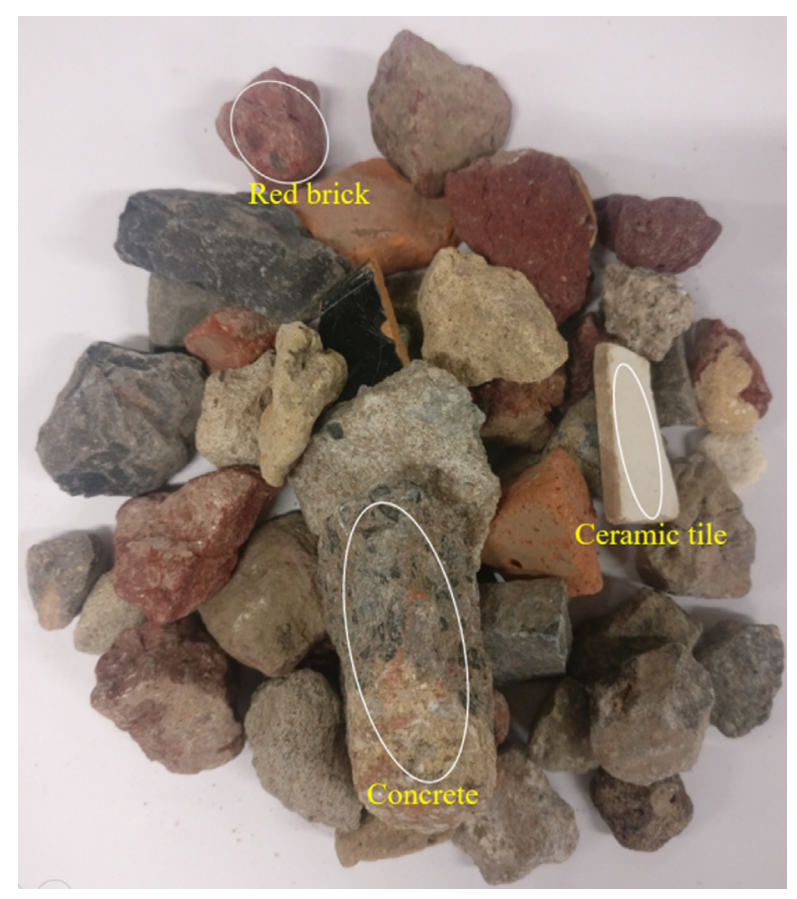

Fig. 1. MRA used in this study.

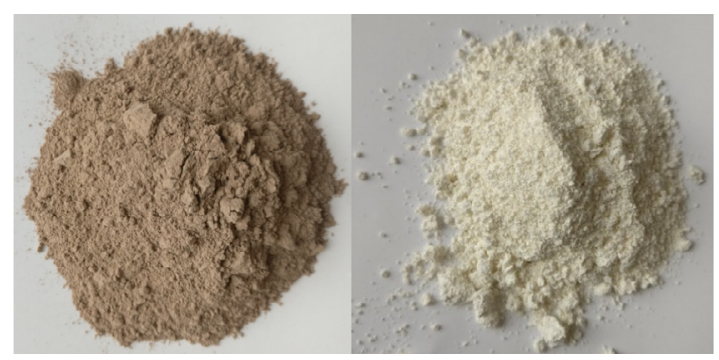

(a) MRAP

(b) Metakaolin

Fig. 2. precursors 


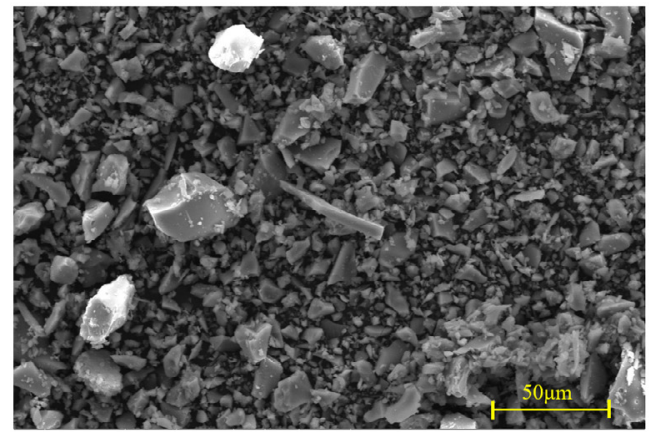

(a) MRAP

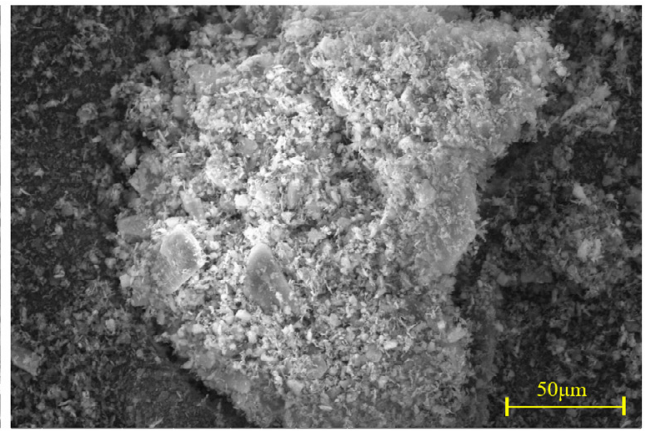

(b) Metakaolin

Fig. 3. Micro morphologies of raw materials.

Table 1

Chemical composition of the precursor materials (Wt\%).

\begin{tabular}{|c|c|c|c|c|c|c|c|c|c|c|c|}
\hline Oxide & $\mathrm{SiO}_{2}$ & $\mathrm{Al}_{2} \mathrm{O}_{3}$ & $\mathrm{CaO}$ & $\mathrm{Fe}_{2} \mathrm{O}_{3}$ & $\mathrm{MgO}$ & $\mathrm{Na}_{2} \mathrm{O}$ & $\mathrm{TiO}_{2}$ & $\mathrm{MnO}_{2}$ & $\mathrm{P}_{2} \mathrm{O}_{5}$ & $\mathrm{SO}_{3}$ & $\mathrm{~K}_{2} \mathrm{O}$ \\
\hline MRAP & 37.8 & 15.2 & 12.5 & 13.7 & 9.7 & 0.9 & 0.7 & 0.1 & 0.2 & 5.7 & 3.1 \\
\hline MK & 61.4 & 32.5 & 0.2 & 0.8 & 2.1 & 0.7 & 0.2 & 0.2 & 0.1 & 0.2 & 0.8 \\
\hline
\end{tabular}

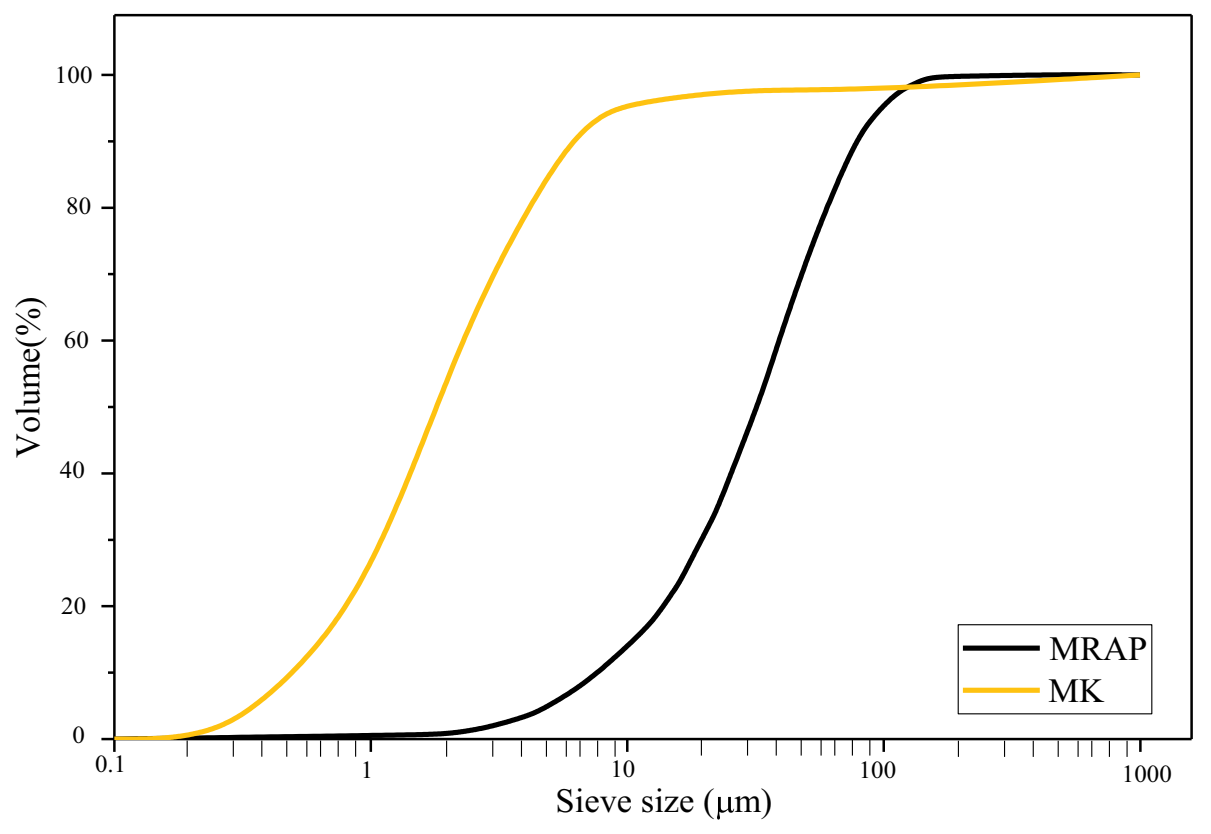

Fig. 4. Particle size distribution curves.

smaller than $10 \mu \mathrm{m}$, while around $87 \%$ of MRAP particle ranges between $10 \mu \mathrm{m}$ and $100 \mu \mathrm{m}$.

The alkaline activator used in the present study was prepared by mixing $\mathrm{Na}_{2} \mathrm{SiO}_{3}$ (14.7\% of $\mathrm{Na}_{2} \mathrm{O}, 29.4 \%$ of $\mathrm{SiO}_{2}$ and $55.9 \%$ of water) and $\mathrm{NaOH}$ solutions with a constant ratio of $1.5\left(\mathrm{Na}_{2} \mathrm{SiO}_{3}\right.$ to $\mathrm{NaOH}$ solution) by mass. The $\mathrm{NaOH}$ solutions with different concentrations were derived by dissolving $\mathrm{NaOH}$ flakes ( $98 \%$ of purity) in potable water. The $\mathrm{Na}_{2} \mathrm{SiO}_{3}$ solution and $\mathrm{NaOH}$ solutions were firstly mixed and then cooled to room temperature prior to being mixed with the solid precursors.

\subsection{Samples design and preparation}

In the present experiment program, a total of 21 geopolymer mixtures were designed. The details of the mixtures can be found in Table 2. The main test variables include the MK replacement ratio (defined as ratio of the MK to the sum of the MK and MRAP by mass), the ambient curing duration before microwave curing, the microwave curing duration, the alkali concentration and solid-to-liquid ratio. Accordingly, the samples were divided into five series:

- The first series (S1-1 to S1-5) aim to investigate the influence of the MK replacement ratio on the efficiency of the microwave curing;

- The second series (S2-1 to S2-5) mainly focus on the effect of the microwave curing duration. The curing duration is defined as the duration of the microwave heating curing, staring from the start-time, which is the complementation of an ambient curing for a certain period ( 3 days for this test series); 
Table 2

Detailed information of all samples.

\begin{tabular}{|c|c|c|c|c|c|}
\hline Samples & MK/(MK + MRAP) (\%) & Alkali concentration (\%) & Solid/liquid ratio & Ambient curing duration (d) & Microwave curing duration (s) \\
\hline S1-1 & 0 & 10 & 2.5 & 3 & 40 \\
\hline S1-2 & 10 & 10 & 2.5 & 3 & 40 \\
\hline S1-3 & 25 & 10 & 2.5 & 3 & 40 \\
\hline S1-4 & 40 & 10 & 2.5 & 3 & 40 \\
\hline S1-5 & 55 & 10 & 2.5 & 3 & 40 \\
\hline S2-1 & 25 & 10 & 2.5 & 3 & 0 \\
\hline S2-2 & 25 & 10 & 2.5 & 3 & 20 \\
\hline S2-3 & 25 & 10 & 2.5 & 3 & 40 \\
\hline S2-4 & 25 & 10 & 2.5 & 3 & 60 \\
\hline S2-5 & 25 & 10 & 2.5 & 3 & 80 \\
\hline S3-1 & 25 & 10 & 2.5 & 1 & 40 \\
\hline S3-2 & 25 & 10 & 2.5 & 3 & 40 \\
\hline S3-3 & 25 & 10 & 2.5 & 5 & 40 \\
\hline S3-4 & 25 & 10 & 2.5 & 7 & 40 \\
\hline S3-5 & 25 & 10 & 2.5 & 9 & 40 \\
\hline S4-1 & 25 & 4 & 2.5 & 3 & 40 \\
\hline S4-2 & 25 & 6 & 2.5 & 3 & 40 \\
\hline S4-3 & 25 & 8 & 2.5 & 3 & 40 \\
\hline S4-4 & 25 & 10 & 2.5 & 3 & 40 \\
\hline S4-5 & 25 & 12 & 2.5 & 3 & 40 \\
\hline S5-1 & 25 & 10 & 2.5 & 3 & 40 \\
\hline S5-2 & 25 & 10 & 3.0 & 3 & 40 \\
\hline S5-3 & 25 & 10 & 3.5 & 3 & 40 \\
\hline S5-4 & 25 & 10 & 4.0 & 3 & 40 \\
\hline S5-5 & 25 & 10 & 4.5 & 3 & 40 \\
\hline
\end{tabular}

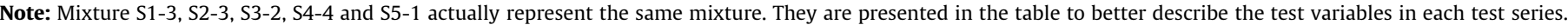

- The third series (S3-1 to S3-5) investigates the influence of the ambient curing duration, i.e., the start-time on the efficiency of the microwave curing. In this series, the samples were firstly cured under ambient temperature $\left(20 \pm 5^{\circ} \mathrm{C}\right)$ for different days (from 1 to 9 days) before the microwave curing;

- The fourth and fifth series (S4-1 to S4-5 and S5-1 to S5-5) were designed to investigate the influence of alkali concentration and solid-to-liquid ratio on the compressive strength of the samples, respectively.

An electric mixer was used to prepare the geopolymer mixtures. The solid precursors were firstly mixed at a rate of $300 \mathrm{rpm}$ for $5 \mathrm{~min}$. Then, the alkaline activator was added into the mixture and mixed for another $10 \mathrm{~min}$. After that, the fresh geopolymer mixture was poured into the steel molds. For each mixture, 3 prisms $(40 \mathrm{~mm} \times 40 \mathrm{~mm} \times 160 \mathrm{~mm}$ ) were cast. The geopolymer mixtures were compacted on a vibration table for $2 \mathrm{~min}$ to remove the entrained air bubbles. After the compaction, the geopolymer mixtures were covered with plastic membranes and kept under ambient conditions (temperature: $20 \pm 2{ }^{\circ} \mathrm{C}$, relative humidity:

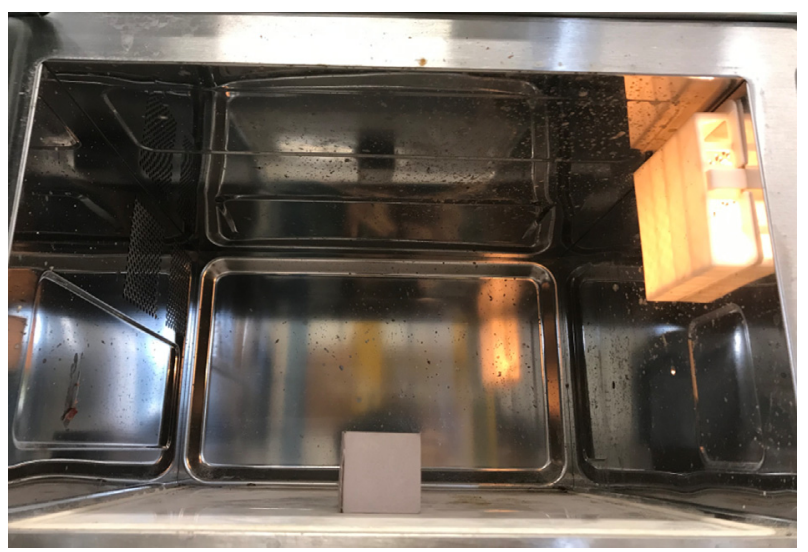

Fig. 5. Microwave oven used in the present study.
$60 \%$ ) for $24 \mathrm{~h}$. After being demolded, each prism was split into two individual parts through a three-point bending test using a semi-automatic testing machine (MATEST, Italy) according to EN 196-1 [27]. The two split parts were cured under ambient conditions up to the target curing age, as shown in Table 2. Then, one part was subjected to a further curing by using of a microwave oven (Menumaster) with a power of $1000 \mathrm{~W}$, as shown in Fig. 5. After reaching the scheduled curing duration, the samples were taken out from the microwave and cooled to ambient temperature. Then, the compressive strength of both the microwave cured part and the counterpart was determined according to EN 196-1[27].

\section{Test results and analysis}

\subsection{The influence of microwave curing duration}

Fig. 6 shows the effect of the microwave curing duration on the compressive strength of the geopolymer samples. The compressive strength increases with the increase of the microwave curing duration until a peak value of $18.6 \mathrm{MPa}$ with a microwave curing duration for $40 \mathrm{~s}$, as shown in Fig. 6(a). A further increase of the microwave curing duration results in a gradual reduction of the compressive strength of the samples. It can be seen from Fig. 6 (b) that the compressive strength of the geopolymer sample with a microwave curing duration of $40 \mathrm{~s}$ increased by $122.29 \%$ in comparison to that of sample without microwave curing; while the sample with $80 \mathrm{~s}$ curing exhibits a compressive strength of $15.95 \mathrm{MPa}$, which is $15 \%$ lower than that of the sample with $40 \mathrm{~s}$ curing. This interesting result indicates that there is an optimum curing duration for the MRAP based geopolymer samples in the present work. This optimal duration can be associated with the power of the microwave, the dimension of the sample, etc, which leaves great scope for future research.

As discussed above, it seems that a microwave heating duration longer than $40 \mathrm{~s}$ does not further increase the compressive strength of the test samples. When the duration is shorter than $40 \mathrm{~s}$, the silicon-aluminate materials in the matrix (after a 3-day ambient curing) are not yet fully activated and then the microwave 


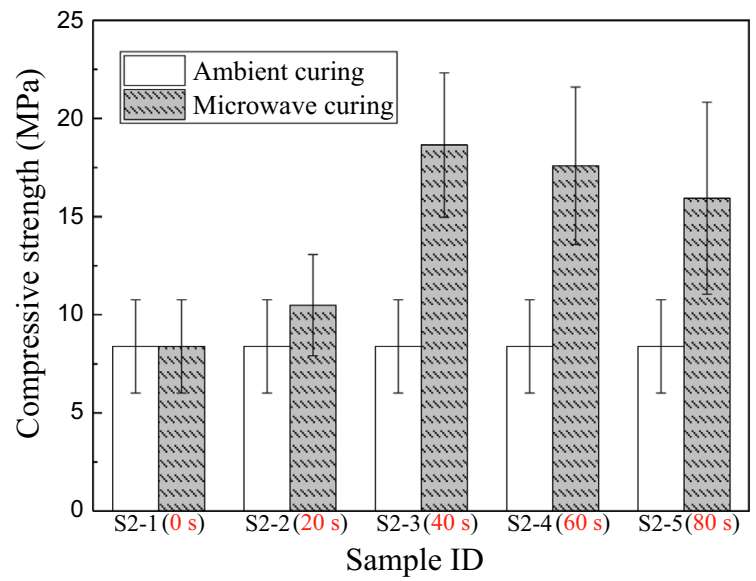

(a) Compressive strength

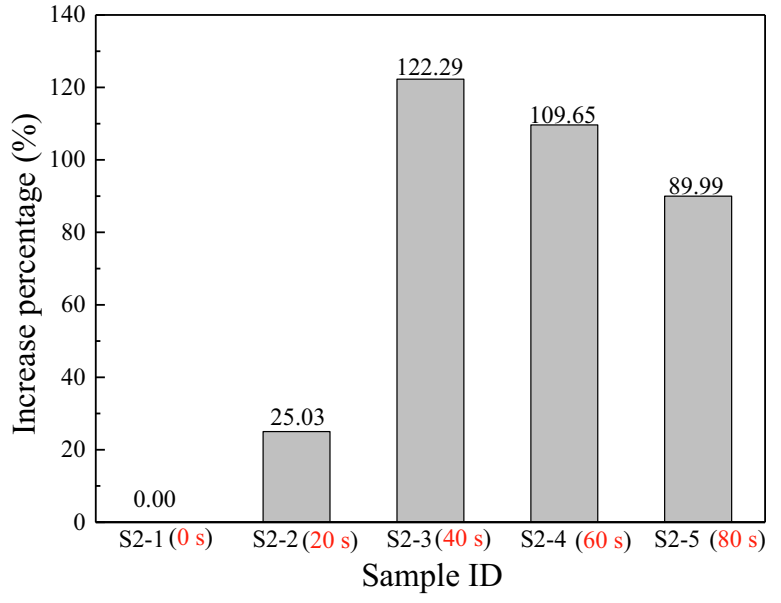

(b) Increase percentage

Fig. 6. Influence of curing duration.

heating effectively accelerates the process. However, when the microwave heating duration exceeds $40 \mathrm{~s}$, the microwave heating may adversely affect the geopolymer mixture in two ways: on the one hand, more silicoaluminates can be activated and denser geopolymer gels can be generated, which enables the sample to achieve higher strength; on the other hand, during the heating progress, vapor can be generated when the water in the geopolymer matrix is heated to a boiling temperature. The vapor generated inside the samples inevitably causes micro cracks because the dense structure of geopolymer limits the volume expansion.

Fig. 7 shows the compressive stress-strain curve of the samples with different curing durations. Ambient-curing sample S2-1 shows approximately $2.1 \%$ plastic deformation. With the increase of microwave duration, the plastic deformation of samples decreased to $1.7 \%$ (40 s) and $1.9 \%$ (80 s), respectively. This proved more brittle substances formation in geopolymer was promoted by microwave cuing.

The typical microstructure of sample S2-5 is shown in Fig. 8. It is noteworthy that numerous microcracks were generated in the sample, verifying the aforementioned analysis. Cracks observed in Fig. 8 were due to the moisture removal during heat curing. The increased reaction product formatted under the microwave irradiation and the consequent development of a more compact

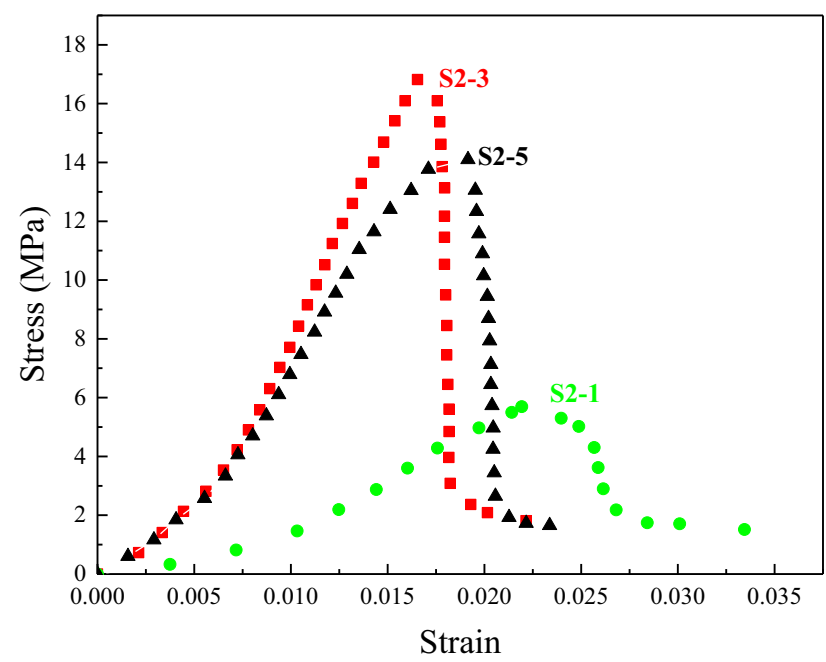

Fig. 7. Stress-strain curves of samples.

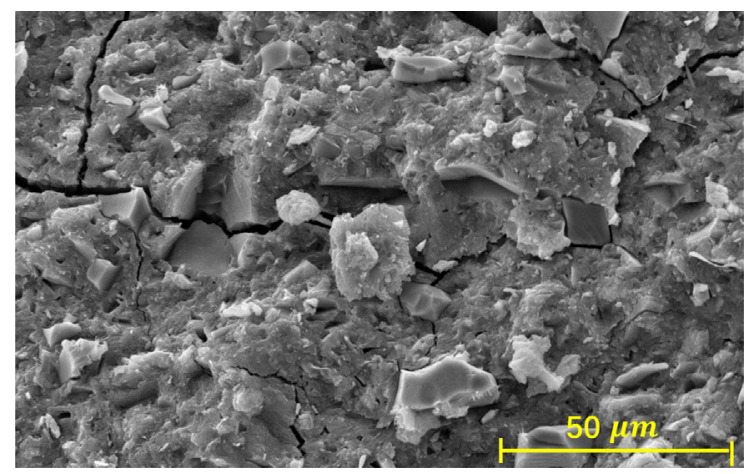

Fig. 8. Microstructure of sample S2-5 after microwave curing.

microstructure would prevent the moisture transport, which is likely to result in strength reduction [28]. As a result, even though a longer microwave heating duration is able to promote the geopolymerisation progress, the compressive strength of the samples may stop rising or even decreases due the cracks generated. Based on the experimental results in this study, the microwave curing duration should be shorter than $40 \mathrm{~s}$.

The XRD patterns of the MRAP and MRAP based geopolymers with different microwave heating durations are shown in Fig. 9. The MRAP consists of different crystalline phase materials such as quartz, calcite, gismondine and spurrite. The peak intensity of the crystalline materials in MRAP reduces or even disappears when compared with that of sample S2-1. This may be explained by the dissolution of the crystalline phase materials in the MRAP and the formation of amorphous aluminosilicate gels. Similar results have been reported elsewhere $[18,29]$. A comparison of sample S2-2 and S2-1 (see Fig. 9) reveals that the intensity of the main peaks further decreases, indicating that more amorphous aluminosilicate gels were formed after a $20 \mathrm{~s}$ microwave curing. Similar phenomenon can be observed when sample S2-3 and S2-1 are compared. Based on the XRD analysis, it suggests that the microwave curing method is an effective way to accelerate the geopolymerization process of the MRAP.

\subsection{Influence of $M K$ replacement ratio}

Fig. 10 shows the influence of the MK replacement ratio ( 0 to $55 \%$ ) on the compressive strength of the geopolymer samples. 


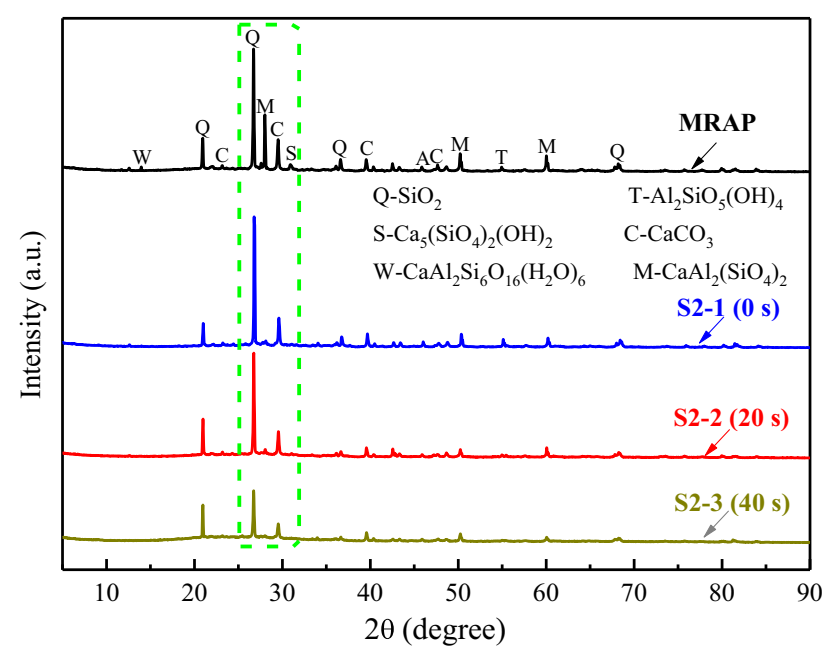

Fig. 9. XRD patterns of MRAP and MRAP based geopolymers. Note: Q- $\mathrm{SiO}_{2}$; $\mathrm{S}-\mathrm{Ca}_{5}\left(\mathrm{SiO}_{4}\right)_{2}(\mathrm{OH})_{2} ; \mathrm{W}-\mathrm{CaAl}_{2} \mathrm{Si}_{6} \mathrm{O}_{16}\left(\mathrm{H}_{2} \mathrm{O}\right)_{6} . \mathrm{T}-\mathrm{Al}_{2} \mathrm{SiO}_{5}(\mathrm{OH})_{4} ; \mathrm{C}-\mathrm{CaCO}_{3} ; \mathrm{M}-\mathrm{CaAl}_{2}\left(\mathrm{SiO}_{4}\right)_{2}$; $\mathrm{A}-\mathrm{Al}_{2} \mathrm{O}_{3}$.

The samples were cured under microwave irradiation for $40 \mathrm{~s}$ after a 3-day ambient curing. Compressive strength of samples rapidly increases with the increase of the MK replacement ratio. For those samples cured by microwave, the compressive strength values are much higher. This proves the potential and efficiency of microwave curing since it significantly increases the compressive strength of geopolymer samples within a short duration (40 s). Previous studies indicate that the microwave radiation enables geopolymer samples to overcome the activation energy of geopolymerization and promotes the dissolution of Si and Al species [24,30], and therefore leads to the accelerated densification and achieves the high compressive strengths of the samples [31].

Meanwhile, it is interesting to find that the efficiency of the microwave curing varies with the MK replacement ratio, as illustrated in Fig. 10(b). With the addition of MK, geopolymer samples exhibit an increased potential to be activated by microwave curing. For example, the compressive strength of mixture S1-1 (without MK addition) increases by $72 \%$ after the microwave curing, while mixture S1-5 with 55\% MK addition shows a compressive strength increase by $160.05 \%$. This can be likely explained that MK introduces more $\mathrm{Si}$ and $\mathrm{Al}$ species into the matrix, the dissolution promoted by microwave curing was, thus, accelerated.

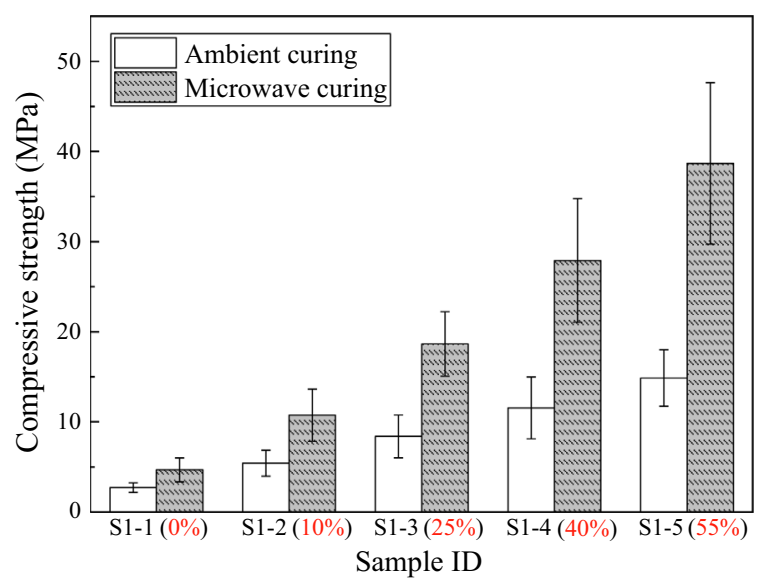

(a) Compressive strength

\subsection{Influence of ambient curing duration}

As presented in Table 2, some geopolymer samples were cured in ambient conditions for different durations (from 1 to 9 days) before being subjected to microwave curing. The aim is to investigate the effect of the starting time on the efficiency of the microwave curing on the geopolymer samples. In this series of samples, the MK replacement ratio and microwave curing duration of the samples were fixed as 0.25 and $40 \mathrm{~s}$, respectively. The measured compressive strength with different ambient curing durations are shown in Fig. 11.

It can be seen that with the increase of ambient curing duration, the microwave curing method tends to be less efficient in improving the compressive strength of the geopolymer samples. For example, the compressive strength for S3-1 (with 1-day ambient curing) increases by $304.11 \%$, while the compressive strength of sample S35 (with 9-day ambient curing) increases by only $75.81 \%$ after the microwave heating. This phenomenon may be attributed to two reasons: Firstly, with the increase of the ambient curing duration, the geopolymerization process becomes more and more complete. The formation procedure of zeolite has been proposed as follows: dissolution of $\mathrm{SiO}_{2}$ and $\mathrm{Al}_{2} \mathrm{O}_{3}$, deposition of aluminosilicate gel, and crystallization of zeolite [32]. Microwave irradiation promotes the dissolution of silicon and aluminum in the early stage. The actives water produced by hydrogen bond breaking under microwave would freely attack $\mathrm{Si}-\mathrm{O}$ and $\mathrm{Al}-\mathrm{O}$ bonds so to furtherly accelerate the dissolution of the glass phase [30]. However, with the longer duration of ambient curing, dissolution would stop before the microwave curing. In addition, microwave irradiation retards the nucleation of zeolite as the nuclei seems to be dissolved again through attacking by active water molecules [24,30]. Therefore, prolonged duration of ambient curing may make the geopolymer mixture be less sensitive to the microwave cuing.

Secondly, a longer ambient curing duration promotes the geopolymerisation process, the increased reaction product formatted and the consequent development of a more compact microstructure would prevent the moisture transport, which is likely to result in more cracks formation, as observed in Fig. 8. Based on the experimental results in this study, ambient curing before the microwave curing should be shorter than 3 days.

\subsection{Influence of alkali concentration}

The influences of the alkali concentration on the compressive strength of the geopolymer samples are presented in Fig. 12. For

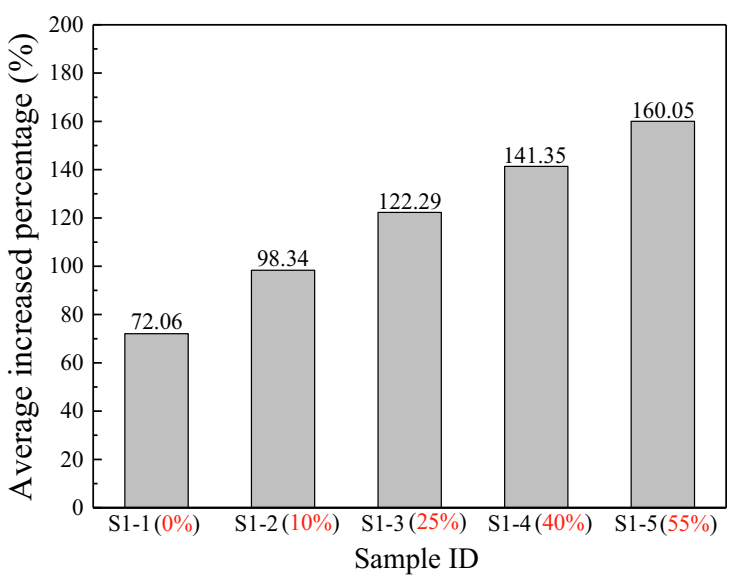

(b) Increase percentage

Fig. 10. Influence of MK replacement ratio on compressive strength. 


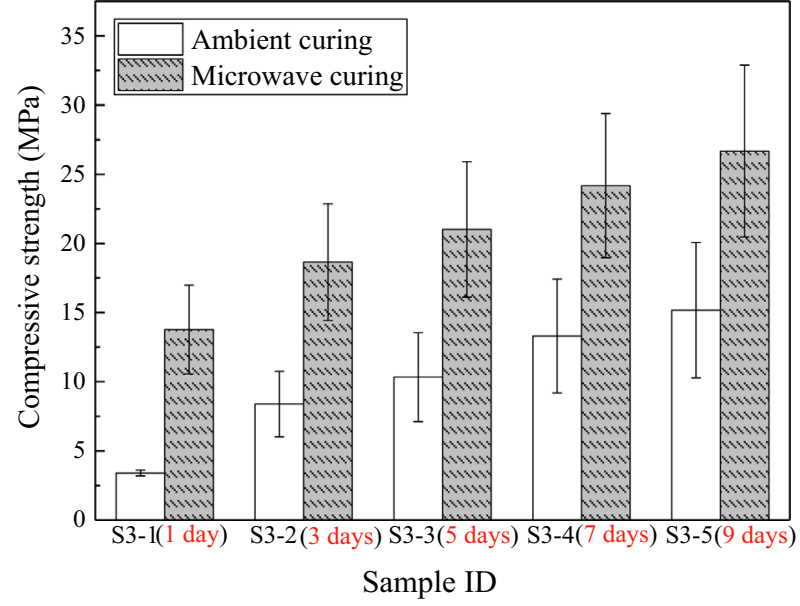

(a) Compressive strength

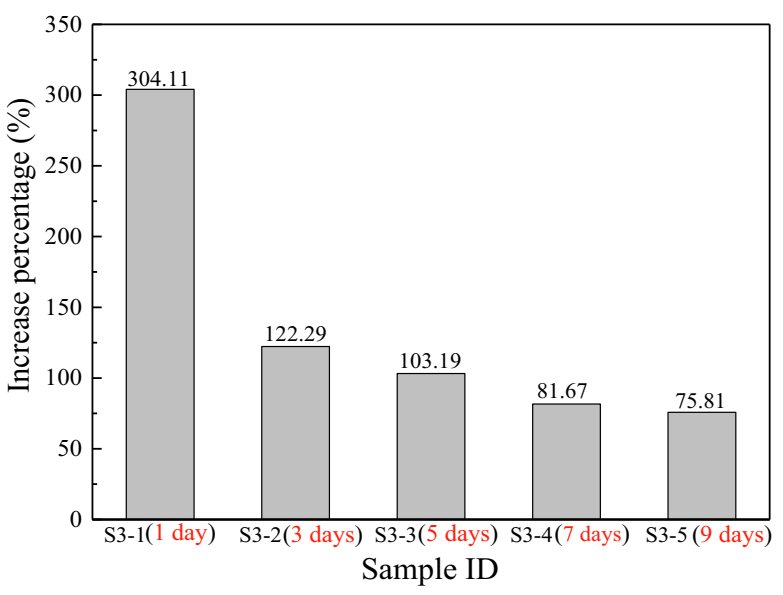

(b) Increase percentage

Fig. 11. Influence of ambient curing duration.

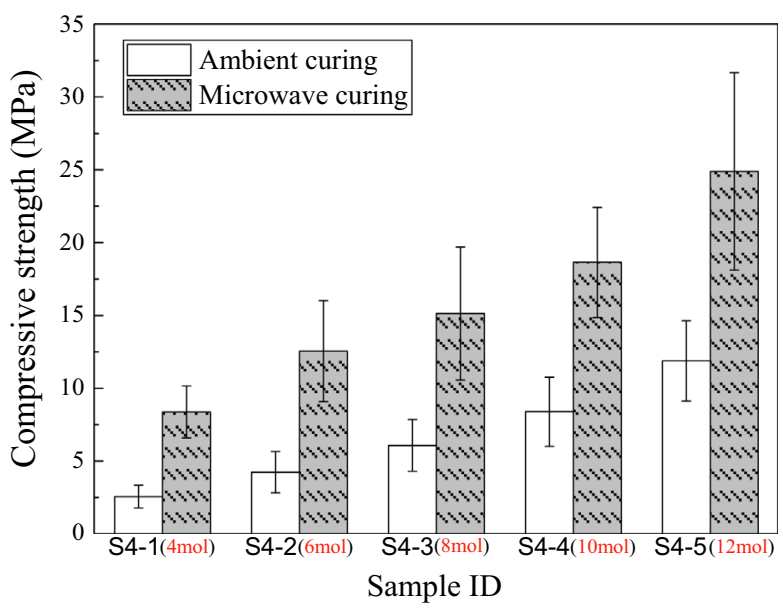

(a) Compressive strength

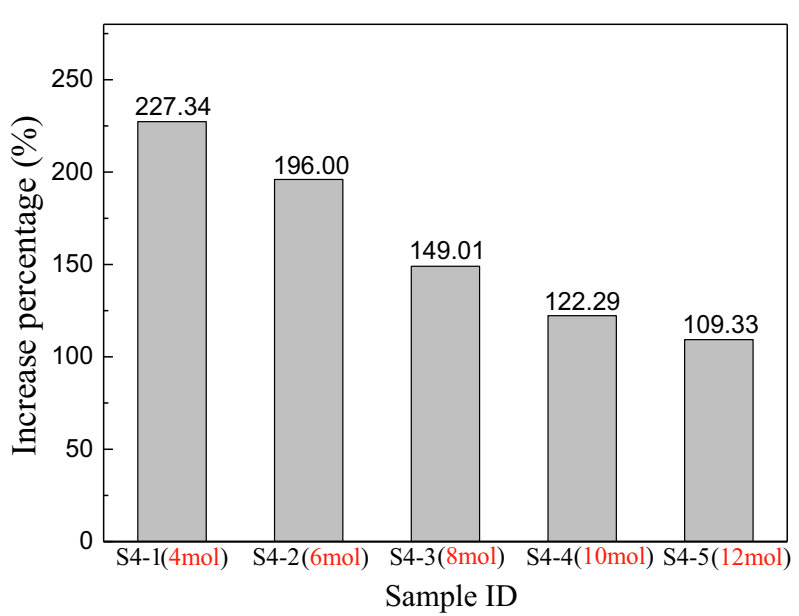

(b) Increase percentage

Fig. 12. Influence of alkali concentration.

samples cured under ambient conditions, the compressive strength increases from 2.56 to $11.89 \mathrm{MPa}$ when the alkali concentration increases from 4 to $12 \mathrm{~mol} / \mathrm{L}$. Increasing the alkali concentration has been widely regarded as an effective method to increase the compressive strength of geopolymers [33,34], since alkaline activator with higher alkali concentration can introduce more $\mathrm{OH}^{-}$into the matrix and promote the $\mathrm{Al}$ and $\mathrm{Si}$ dissolution. In addition, the boiling point of the solution increases with the concentration. Some studies showed that a 5 to $15{ }^{\circ} \mathrm{C}$ boiling point rise was observed when the $\mathrm{NaOH}$ concentration increases from 4 to $10 \mathrm{M}$ [35]. Therefore, with a higher concentration of the activator, moisture tends to be less readily removed from samples cured under the microwave irradiation, and hence the cracks generated due to the moisture removal would decrease.

Fig. 12(b) shows the effect of the alkaline solution concentration on the compressive strength increase of the microwave cured samples. The results indicate that the microwave curing method is more efficient in improving the compressive strength of samples with lower alkali concentration. As can be seen from Fig. 12(b), the compressive strength of sample S4-1 increases by $227.34 \%$ with microwave curing application, while the increase for sample
S4-5 is only $109.33 \%$. The reaction rate of geopolymer is faster with higher solution concentration. Therefore, the dissolution of silica and aluminum is nearly completed before the microwave curing, and thus the effect of microwave heating is limited. For the samples with lower alkalinity solution, cracks creation due to the loss of moisture, as shown in Fig. 8, is more than compensated for by the faster dissolution rates, resulting in better strength enhancement under microwave irradiation. Based on this interesting result, it can be concluded that a combination of alkali solution of low concentration and microwave curing method might provide a novel method to develop more economical geopolymers.

\subsection{Influence of solid-to-liquid ratio}

The solid-to-liquid ratio in the geopolymer mixture reflects the relative amount of the $\mathrm{OH}^{-}$. Fig. 13(a) shows the influence of the solid-to-liquid ratio on the compressive strength of samples. With the increase of the solid-to-liquid ratio from 2.5 to 4.5 , the compressive strength of the samples cured at ambient conditions dramatically decreased. Insufficient $\mathrm{OH}^{-}$content should be responsible for the reduced strength since less $\mathrm{Al}$ and Si species 


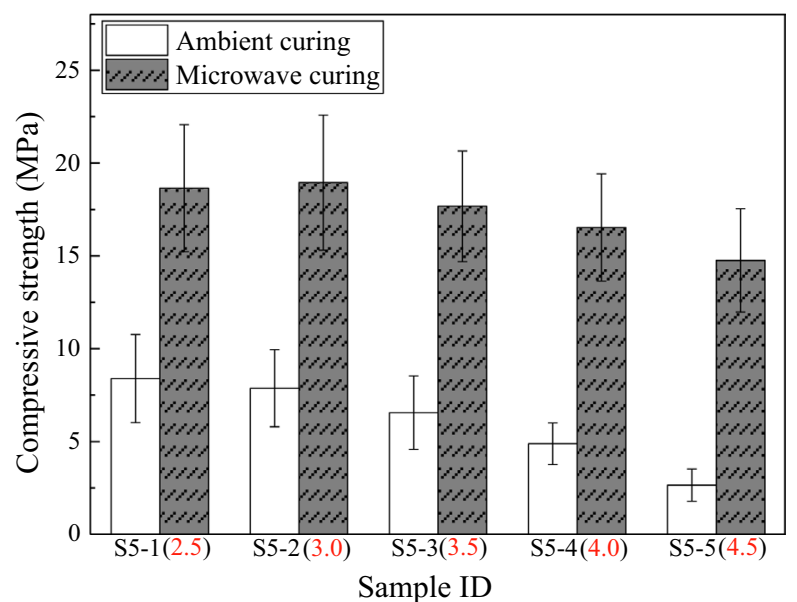

(a) Compressive strength

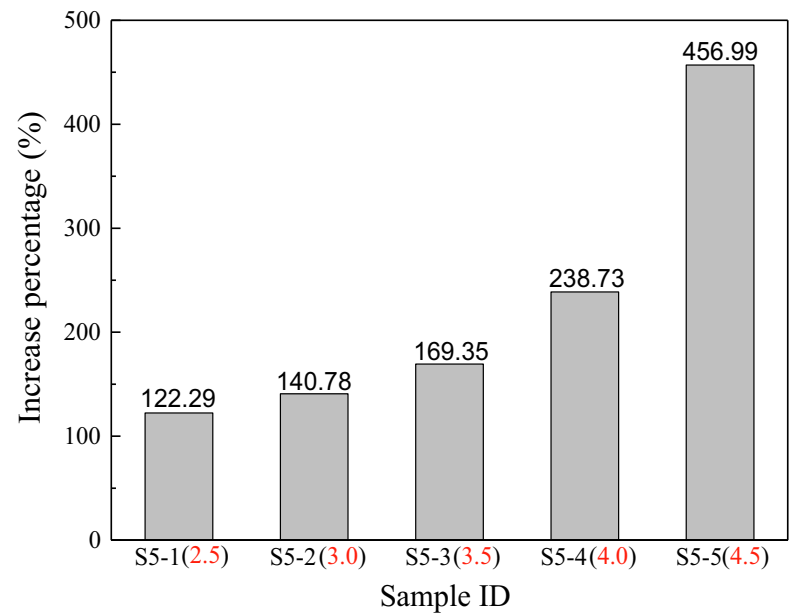

(b) Increase percentage

Fig. 13. Influence of solid-to-liquid ratio.

can be dissolved from the precursor materials. While for the microwave cured samples, a slight drop in terms of compressive strength can be observed. Fig. 13(b) shows the difference in the compressive strength between the microwave cured samples and ambient cured samples significantly increases with the increase of solidto-liquid ratio, leading to the fact that reducing the $\mathrm{OH}^{-}$content has less effect on the compressive strength of the microwave cured samples, as revealed in Fig. 13(a). A possible reason may be assigned to actives water produced by hydrogen bond breaking under microwave would freely attack $\mathrm{Si}-\mathrm{O}$ and $\mathrm{Al}-\mathrm{O}$ bonds so to furtherly accelerate the dissolution of the glass phase [30]. Thus, even though the mixture contains less alkaline activator, the water molecules containing $\mathrm{OH}^{-}$still has a great opportunity to dissolve $\mathrm{Al}$ and $\mathrm{Si}$ atoms as the water molecules keep spinning and moving under the microwave curing condition. By contrast, for those samples subjected to ambient curing conditions, the water molecules inside the samples move slowly thus the $\mathrm{Al}$ and $\mathrm{Si}$ atoms have less chance to encounter the $\mathrm{OH}^{-}$. In addition, the increased reaction product formation under microwave irradiation was negated by the increase in cracks fraction due to increased moisture loss of samples with higher solid-to-liquid ratio.

\section{Environmental impact and cost-benefit analysis}

Geopolymer has been regarded as an alternative showing enhanced green potential in comparison to traditional Portland cement. The key reason why geopolymer has been gaining increasing interest is related to its potential to reduce $\mathrm{CO}_{2}$ emissions [36]. However, traditional oven curing used in geopolymers manufacture may dramatically evoke a much higher $\mathrm{CO}_{2}$ emission, which greatly reduces the environmental benefits of this material. In order to investigate to what extent can the microwave curing method benefit the production of geopolymer, a cost impact analysis and an environment performed by quantitively comparing the $\mathrm{CO}_{2}$ emissions generated by traditional oven curing geopolymer (TG) and microwave oven curing geopolymer (MG) were conducted in this study.

Damineli [37] proposed that the eco-efficiency of cement can be evaluated by a relevant indicator. In this paper, the following $\mathrm{CO}_{2}$ intensity $\left(C_{i}\right)$ was proposed to assess the eco-efficiency of geopolymer:

$C_{i}=C_{d} / f_{c}^{\prime}$ where $C_{d}$ is the resulted $\mathrm{CO}_{2}$ emissions $\left(\mathrm{kg} / \mathrm{m}^{3}\right)$ from the curing and $f_{c}^{\prime}$ is the compressive strength of geopolymer samples.

A group of geopolymer paste samples (25\% MK replacement, $10 \mathrm{~mol} / \mathrm{l}$ alkali concentration and 2.5 solid-to-liquid ratio) were cast and were subjected to traditional oven curing. An electric curing oven $(1000 \mathrm{~W})$ was used and the curing temperature was set as $75^{\circ} \mathrm{C}$. An electric meter was connected to the oven for accurately recording its electric consumption. The compressive strength development of the samples is shown in Fig. 14.

The $\mathrm{CO}_{2}$ emission generated during the curing was estimated based on the consumed energy. In Europe, one unit of electricity consumption $(\mathrm{KW} \cdot \mathrm{h})$ approximately results in an emission of $1.35 \mathrm{~kg} \mathrm{CO}_{2}[23,38]$. Based on this information and the compressive strength shown in Fig. 14, the $\mathrm{CO}_{2}$ intensity $\left(C_{i}\right)$ of TG is therefore obtained, as shown in Fig. 15.

Fig. 15 indicates that the $\mathrm{CO}_{2}$ intensity $\left(C_{i}\right)$ of the TG gradually increases with the curing duration. As for $\mathrm{MG}$, the calculated $\mathrm{CO}_{2}$ intensity of the samples cured for $20 \mathrm{~s}, 40 \mathrm{~s}, 60 \mathrm{~s}, 80 \mathrm{~s}$ are 3.19 , $3.59,5.71$ and 8.40 , respectively, which are much lower than that of TG samples.

The cost-benefit analysis of the geopolymer was performed by quantitively comparing the energy consumption generated by TG and MG. Similarly, a relevant indicator $C_{c}$ was defined to evaluate the cost-benefit efficiency of geopolymer.

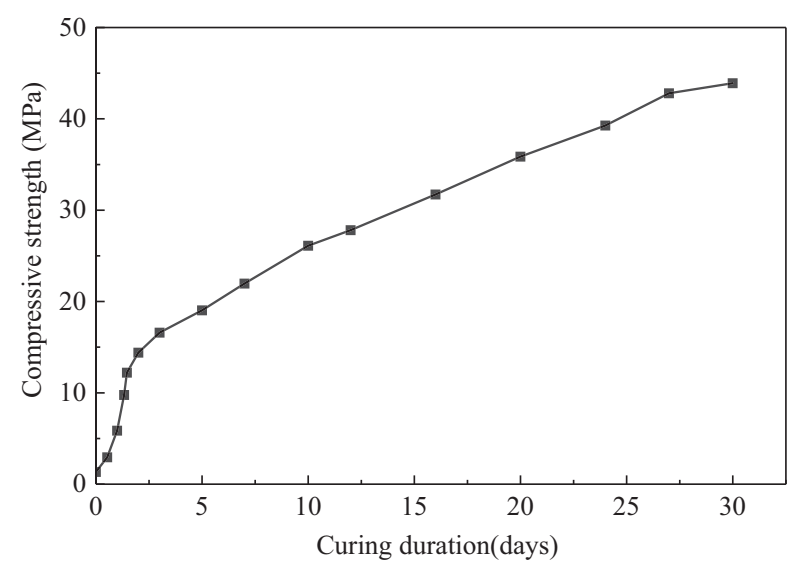

Fig. 14. Compressive strength of TG samples. 


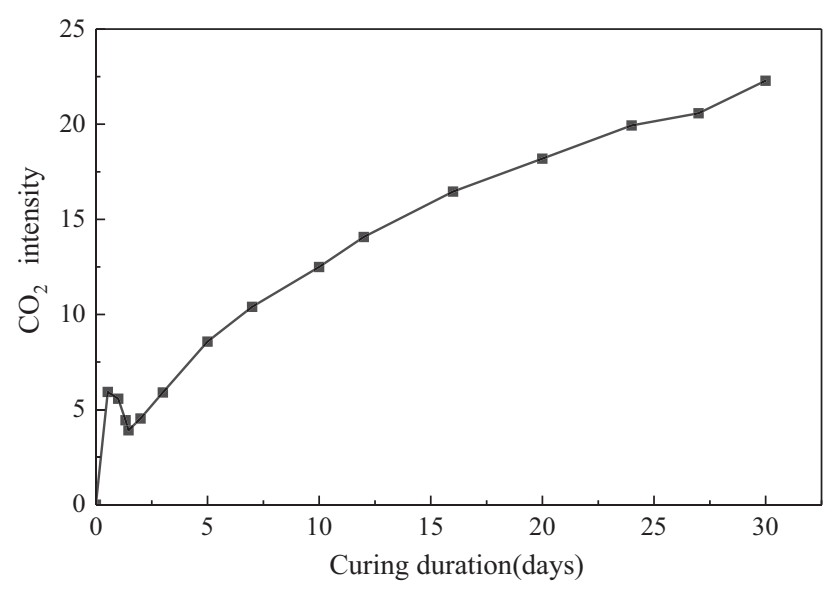

Fig. 15. $\mathrm{CO}_{2}$ intensity of electrical oven cured samples.

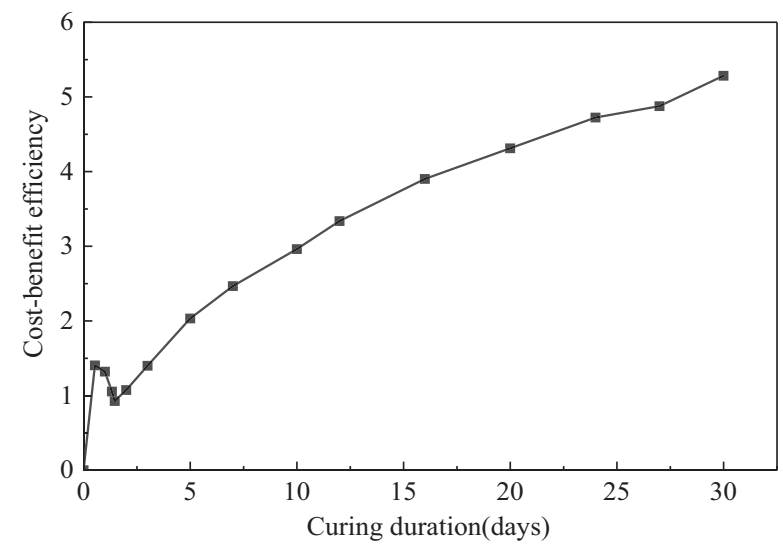

Fig. 16. The cost-benefit efficiency of oven curing samples.

$C_{c}=C_{e} / f_{c}^{\prime}$

where, $C_{e}$ is the total cost of geopolymer $\left(\mathrm{USD} / \mathrm{m}^{3}\right)$ and $f_{c}^{\prime}$ is the compressive strength of samples.

Based on the strength values shown in Fig. 14, the cost-benefit efficiency $\left(C_{c}\right)$ of TG can be estimated, as shown in Fig. 16 . The electricity price in Belgium is around $0.32 \mathrm{USD} / \mathrm{KW} \mathrm{h}$. The cost-benefit efficiency $\left(C_{c}\right)$ of TG gradually increases with the duration, as shown in Fig. 16. While the cost-benefit efficiency values of MG samples cured for $20 \mathrm{~s}, 40 \mathrm{~s}, 60 \mathrm{~s}, 80 \mathrm{~s}$ were $0.75,0.85,1.35$ and 1.99 , respectively. Compared with traditional oven curing method, the microwave curing method greatly reduces the energy consumption cost.

It is worth note that the time cost savings should also be taken into account. According to the test results shown in Figs. 6 and 14, the samples cured in traditional oven took approximately 5 days to achieve a similar compressive strength of MG samples cured for $40 \mathrm{~s}$, indicating that microwave curing significantly shortens the required curing duration. Similar conclusion has been reported in previous studies [25,39]. With microwave curing method, production efficiency of geopolymer can be further improved. That, in turn, is highly beneficial, for it shortens the time to placement on the work site, enhancing the manufacturing pace, and greatly reducing the cost.

\section{Conclusions and remarks}

This paper presents a laboratory study on the feasibility of employing the microwave curing method to enhance the perfor- mance of geopolymer using mixed recycled aggregate powder (MRAP) as source material. The effect of different parameters on the efficiency of the microwave curing method was investigated. Within the scope of this work, the following conclusions can be drawn:

1. It is feasible to increase the compressive strength of the MRAP based geopolymers via the microwave curing method. By using this method, the geopolymerisation progress of MRAP based geopolymer can be effectively promoted, leading to a compressive strength enhancement of geopolymer samples. The efficiency of the microwave curing be increased with the MK (metakaolin) addition.

2. The duration of the microwave curing significantly affected the compressive strength of the MRAP based geopolymer. Up to an optimal curing condition, the compressive strength of the samples increased with the curing duration. However, a further increase of the curing duration resulted in a reduction of the compressive strength. The optimal microwave curing duration is found to be $40 \mathrm{~s}$ in the present research.

3. An earlier starting time (ambient curing duration before microwave curing) made the micro curing method more efficient and enabled sample to achieve a higher compressive strength. Based on the experimental results in this study, ambient curing duration before the microwave curing is recommended to be shorter than 3 days.

4. The efficiency of microwave curing increased with a lower alkali solution, implying a possible new approach to make geopolymers through a combination of microwave curing method and low concentration alkaline solution.

5. Microwave curing is more effective for MRAP based geopolymer samples with higher solid-liquid ratio.

6. Microwave curing can significantly increase the eco-efficiency but greatly reduce the production cost of geopolymers by reducing energy consumption and increasing curing efficiency.

\section{CRediT authorship contribution statement}

Jiawei Tan: Investigation, Writing - original draft. Jingming Cai: Writing - original draft. Linchong Huang: Review \& Editing. Qiuning Yang: Review \& Editing. Mingjie Mao: Review \& Editing. Jiabin Li: Review \& Editing.

\section{Declaration of Competing Interest}

The authors declare that they have no known competing financial interests or personal relationships that could have appeared to influence the work reported in this paper.

\section{Acknowledgments}

This work has been financially supported by Lvnong Chair in Construction Waste Recycling at KU Leuven, sponsored by Hangzhou Lvnong Environment Engineering Co, Ltd, the Natural Science Foundation of China (No. 51908117) and the Jiangsu Planned Projects for Postdoctoral Research Funds (2019K042).

\section{References}

[1] Z. Xiong, Q. Cai, F. Liu, L. Li, Y. Long, Dynamic performance of RAC-filled doubleskin tubular columns subjected to cyclic axial compression, Constr. Build.

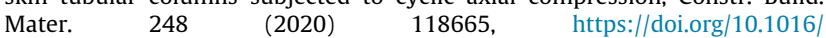
j.conbuildmat.2020.118665.

[2] Ec, 2018. Construction and demolition waste (CDW) [WWW document]. URL http://ec.europa.eu/environment/waste/construction demolition.htm.

[3] B. Mas, A. Cladera, T.D. Olmo, F. Pitarch, Influence of the amount of mixed recycled aggregates on the properties of concrete for non-structural use 
Constr. Build. Mater. 27 (1) (2012) 612-622, https://doi.org/10.1016/ j.conbuildmat.2011.06.073.

[4] T.C. Hansen, Recycling of Demolished Concrete and Masonry, CRC Press, 1992.

[5] R.K. Dhir, C.Q. Lye, ICE Themes Recycled Aggregates: Use in Concrete, ICE Press, 2019.

[6] F. Pacheco-Torgal, Y. Ding, F. Colangelo, R. Tuladhar, A. Koutamanis, Advances in Construction and Demolition Waste Recycling: Management, Processing and Environmental Assessment, Woodhead Publishing, 2020.

[7] L.G. Li, Z.Y. Zhuo, J. Zhu, A.K.H. Kwan, Adding ceramic polishing waste as paste substitute to improve sulphate and shrinkage resistances of mortar, Powder Technol. 362 (2020) 149-156, https://doi.org/10.1016/j.powtec.2019.11.117.

[8] J.-J. Zeng, X.-W. Zhang, G.-M. Chen, X.-M. Wang, T. Jiang, FRP-confined recycled glass aggregate concrete: concept and axial compressive behavior, J. Build. Eng. 30 (2020) 101288, https://doi.org/10.1016/j.jobe.2020.101288.

[9] F. Agrela, M. Sánchez de Juan, J. Ayuso, V.L. Geraldes, J.R. Jiménez, Limiting properties in the characterisation of mixed recycled aggregates for use in the manufacture of concrete, Constr. Build. Mater. 25 (10) (2011) 3950-3955, https://doi.org/10.1016/j.conbuildmat.2011.04.027.

[10] M. Albitar, M.S. Mohamed Ali, P. Visintin, M. Drechsler, Durability evaluation of geopolymer and conventional concretes, Constr. Build. Mater. 136 (2017) 374-385, https://doi.org/10.1016/j.conbuildmat.2017.01.056.

[11] P. Duan, C. Yan, W. Zhou, Compressive strength and microstructure of fly ash based geopolymer blended with silica fume under thermal cycle, Cem. Concr.

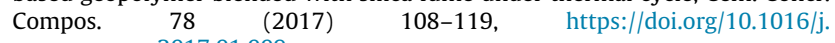
cemconcomp.2017.01.009.

[12] E.J. Guades, Experimental investigation of the compressive and tensile strengths of geopolymer mortar: The effect of sand/fly ash (S/FA) ratio, Constr. Build. Mater. 127 (2016) 484-493, https://doi.org/10.1016/ j.conbuildmat.2016.10.030.

[13] K. Pasupathy, M. Berndt, J. Sanjayan, P. Rajeev, D.S. Cheema, Durability of low calcium fly ash based geopolymer concrete culvert in a saline environment, Cem. Concr. Res. 100 (2017) 297-310, https://doi.org/10.1016/ j.cemconres.2017.07.010.

[14] Y.H.M. Amran, R. Alyousef, H. Alabduljabbar, M. El-Zeadani, Clean production and properties of geopolymer concrete; a review, J. Cleaner Prod. 251 (2020) 119679, https://doi.org/10.1016/j.jclepro.2019.119679.

[15] Alkali activated materials: state-of-the-art report, RILEM TC 224-AAM[M]. Springer Science \& Business Media, 2013.

[16] N. Hamdi, I. Ben Messaoud, E. Srasra, Production of geopolymer binders using clay minerals and industrial wastes, C. R. Chim. 22 (2-3) (2019) 220-226, https://doi.org/10.1016/j.crci.2018.11.010.

[17] R.A. Robayo-Salazar, J.F. Rivera, R. Mejía de Gutiérrez, Alkali-activated building materials made with recycled construction and demolition wastes, Constr. Build. Mater. 149 (2017) 130-138, https://doi.org/10.1016/ j.conbuildmat.2017.05.122.

[18] J. Tan, J. Cai, X. Li, J. Pan, J. Li, Development of eco-friendly geopolymers with ground mixed recycled aggregates and slag, J. Cleaner Prod. 256 (2020) 120369, https://doi.org/10.1016/j.jclepro.2020.120369.

[19] T. Bakharev, Geopolymeric materials prepared using Class F fly ash and elevated temperature curing, Cem. Concr. Res. 35 (6) (2005) 1224-1232, https://doi.org/10.1016/j.cemconres.2004.06.031.

[20] S. Dadsetan, H. Siad, M. Lachemi, M. Sahmaran, Construction and demolition waste in geopolymer concrete technology: a review, Mag. Concr. Res. 71 (23) (2019) 1232-1252, https://doi.org/10.1680/jmacr.18.00307.

[21] T. Xie, T. Ozbakkaloglu, Behavior of low-calcium fly and bottom ash-based geopolymer concrete cured at ambient temperature, Ceram. Int. 41 (4) (2015) 5945-5958, https://doi.org/10.1016/j.ceramint.2015.01.031.

[22] Parveen, D. Singhal, M.T. Junaid, B.B. Jindal, A. Mehta, Mechanical and microstructural properties of fly ash based geopolymer concrete incorporating alccofine at ambient curing, Constr. Build. Mater. 180 (2018) 298-307, https:// doi.org/10.1016/j.conbuildmat.2018.05.286.

[23] L.K. Turner, F.G. Collins, Carbon dioxide equivalent (CO2-e) emissions: a comparison between geopolymer and OPC cement concrete, Constr. Build Mater. $43 \quad$ (2013) 125-130, https://doi.org/10.1016/ j.conbuildmat.2013.01.023.

[24] P. Chindaprasirt, U. Rattanasak, S. Taebuanhuad, Role of microwave radiation in curing the fly ash geopolymer, Adv. Powder Technol. 24 (3) (2013) 703-707. https://doi.org/10.1016/j.apt.2012.12.005.

[25] P. Chindaprasirt, U. Rattanasak, S. Taebuanhuad, Resistance to acid and sulfate solutions of microwave-assisted high calcium fly ash geopolymer, Mater Struct. 46 (3) (2013) 375-381, https://doi.org/10.1617/s11527-012-9907-1.

[26] A. Graytee, J.G. Sanjayan, A. Nazari, Development of a high strength fly ashbased geopolymer in short time by using microwave curing, Ceram. Int. 44 (7) (2018) 8216-8222, https://doi.org/10.1016/j.ceramint.2018.02.001.

[27] EN T S. 196-1. Methods of testing cement-Part 1: Determination of strength [J]. European Committee for Standardization, 2005, 26.

[28] J. Somaratna, D. Ravikumar, N. Neithalath, Response of alkali activated fly ash mortars to microwave curing, Cem. Concr. Res. 40 (12) (2010) 1688-1696, https://doi.org/10.1016/j.cemconres.2010.08.010.

[29] S. Hanjitsuwan, S. Hunpratub, P. Thongbai, S. Maensiri, V. Sata, P. Chindaprasirt, Effects of $\mathrm{NaOH}$ concentrations on physical and electrical properties of high calcium fly ash geopolymer paste, Cem. Concr. Compos. 45 (2014) 9-14, https://doi.org/10.1016/j.cemconcomp.2013.09.012.

[30] M. Inada, H. Tsujimoto, Y. Eguchi, N. Enomoto, J. Hojo, Microwave-assisted zeolite synthesis from coal fly ash in hydrothermal process, Fuel (2005), https://doi.org/10.1016/j.fuel.2005.02.002.

[31] T. Ebadzadeh, M.H. Sarrafi, E. Salahi, Microwave-assisted synthesis and sintering of mullite, Ceram. Int. 35 (8) (2009) 3175-3179, https://doi.org/ 10.1016/j.ceramint.2009.05.013.

[32] P. Rożek, M. Król, W. Mozgawa, Geopolymer-zeolite composites: a review, J. Cleaner Prod. 230 (2019) 557-579, https://doi.org/10.1016/j. jclepro.2019.05.152.

[33] J. He, J. Zhang, Y. Yu, G. Zhang, The strength and microstructure of two geopolymers derived from metakaolin and red mud-fly ash admixture: A comparative study, Constr. Build. Mater. 30 (2012) 80-91, https://doi.org/ 10.1016/j.conbuildmat.2011.12.011.

[34] X. Guo, H. Shi, W.A. Dick, Compressive strength and microstructural characteristics of class C fly ash geopolymer, Cem. Concr. Compos. 32 (2) (2010) 142-147, https://doi.org/10.1016/j.cemconcomp.2009.11.003.

[35] M. Bialik, P. Sedin, H. Theliander, Boiling point rise calculations in sodium salt solutions, Ind. Eng. Chem. Res. 47 (4) (2008) 1283-1287, https://doi.org/ 10.1021 /ie070564c.

[36] J.L. Provis, Geopolymers and other alkali activated materials: why, how, and what?, Mater. Struct. 47 (1-2) (2014) 11-25, https://doi.org/10.1617/s11527013-0211-5.

[37] B.L. Damineli, F.M. Kemeid, P.S. Aguiar, V.M. John, Measuring the eco-efficiency of cement use, Cem. Concr. Compos. 32 (8) (2010) 555-562, https://doi.org/ 10.1016/j.cemconcomp.2010.07.009.

[38] European Commission. Commission Regulation (EU) No 601/2012 of 21/06/ 2012 on the monitoring and reporting of greenhouse gas emissions pursuant to Directive 2003/87/EC of the European Parliament and of the Council, OJEC 2012, L 181: 30-104. http://data.europa.eu/eli/reg/2012/601/oj.

[39] M.S. El-Feky, Mohamed Kohail, A.M. El-Tair, M.I. Serag, Effect of microwave curing as compared with conventional regimes on the performance of alkali activated slag pastes, Constr. Build. Mater. 233 (2020) 117268, https://doi.org/ 10.1016/j.conbuildmat.2019.117268. 